\title{
Biologia de Neotrioza tavaresi Crawford, 1925 (Hemiptera, Psyllidae), galhador da folha do araçazeiro (Psidium cattleianum)
}

\author{
C. A. Butignol ${ }^{1}$ \\ J. H. Pedrosa-Macedo
}

\begin{abstract}
Biology of the leaf gall inducer Neotrioza tavaresi Crawford, 1925 (Hemiptera, Psyllidae) on strawberry guava tree (Psidium cattleianum). A field study was conducted in Curitiba region, State of Paraná, southern Brazil, to describe the life cycle of Neotrioza tavaresi Crawford, 1925, a leaf galling insect in strawberry guava trees (Psidium cattleianum). Three cycles were observed $(1997,1998,1999)$ during regular field trips and the insects were observed in Piraquara municipality, where 15 samples with 50 infested leaves were sampled in the 1997-98 cycle. Galls were dissected for detailed studies. Neotrioza tavaresi has a univoltine cycle in which adult individuals were found inside the galls from August onwards. The sexually mature insects with sex ratio 1, emerged from the galls after their dehiscence caused by feeding of the adult insects on the gall walls. Adult emergence started in early October and ended by early December, with its peak in November. Copulation took place as soon as adults exit the gall and egg laying started the next day. Females had more than 100 ovarioles containing $218.7 \pm 44.7$ ( $\mathrm{n}=50$ ) fully formed eggs. This indicated the short sexual adult life-span (aprox. 5-7 days) of the species, also characterized by a concentrated oviposition. Adult individuals fed and laid their eggs on younger shoots of the plant. The bottoms of the yellowish eggs were inserted into the leaf tissue, mainly on its adaxial edge $(78.1 \%)$. The nymphs hatched and, as they fed on the adaxial side of expanding leaves, modified the cell growth pattern and the roundshape galls developed on the adaxial side with one insect inside. The gall wall showed distinct layers, with the inner one suppliyng the food to the insects, and the outer layer supplying gall protection. Nymphs went through five instars and the exuviae remained stuck on a ball of wax inside the gall. All parasitoids found were Hymenoptera belonging to Chalcidoidea: Eulophidae (1 sp), Pteromalidae (2 spp) and Encyrtidae ( $3 \mathrm{spp}$ ). The findings suggest that leaf gall inducer and parasitoids insects and plant life cycles are closely connected and both leaf sprouting and gall opening seem to be triggered by the same environmental and plant conditions. The high abundance of shoots may favor insect performance as adult individuals can easily find an ideal place for feeding, copulating and laying eggs.
\end{abstract}

KeYwords. Insect/plant relationship; life cycle; natural enemies; Psyllidae.

\section{INTRODUÇÃO}

O araçazeiro, Psidium cattleianum Sabine, 1821 (Magnoliatae, Myrtaceae, Myrtoideae) é originário da região meridional da América do Sul e, embora tenha uma ampla dispersão, suas maiores populações se encontram em formações vegetais próximas à faixa litorânea (LEGRAND \& KLEIN 1977). Devido à sua beleza e aos seus frutos, esta planta foi levada para várias regiões tropicais do mundo, tornando-se indesejável em muitos locais (WIKLER 1999). Com o objetivo de selecionar insetos fitófagos adequados para controle biológico clássico, muitas espécies foram estudadas para verificar seu potencial de emprego. Dentre os fitófagos, os cecidógenos ou galhadores, se destacam pela grande seletividade na sua alimentação, uma vez que o hospedeiro deve apresentar respostas adequadas para o estabelecimento da infestação (RoHFRITSCH 1992; WeIS et al. 1988) e apreciáveis danos nos seus hospedeiros (Abrahamson \& Mccrea 1986; Harris \& Shorthouse 1996).

A capacidade de formar galhas ou cecídeas, é uma das formas mais eficientes de utilização dos vegetais e os insetos que adquiriram tal estratégia de vida, resultado de um longo período de adaptação, aumentaram continuamente seu número de espécies (Roskam 1992; Price 1997). Dentre o grupo dos insetos galhadores (cecidógenos), Hemiptera, especialmente

1. Departamento de Fitotecnia, CCA, Universidade Federal de Santa Catarina. Caixa Postal 476, 88040-900 Florianópolis - SC, Brasil. Endereço eletrônico: butignol@cca.ufsc.br

2. Departamento de Ciências Florestais, SCA, Universidade Federal do Paraná. Av. Pref. Lotário Meissner 3400, 80210-170 Curitiba - PR, Brasil. Endereço eletrônico: johpema@netpar.com.br 
os Sternorrhyncha, possuem muitos taxa com esta característica de vida. Em Psyllidae, família largamente distribuída e com grande número de espécies na região pantropical, ocorrem várias espécies de cecidógenos (Hodkinson 1984). Segundo este autor, suas galhas podem ser agrupadas em quatro tipos de classes em função das distintas alterações dos tecidos, indo do enrolamento e deformação da parte atacada até a formação de uma galha complexa e fechada, com grandes modificações estruturais, com vários tipos de camadas de células em suas paredes e complexos sistemas de abertura.

As vantagens desta associação inseto/planta da qual resulta a galha, são favoráveis ao inseto, pelo aumento da qualidade nutricional dos tecidos modificados pelo efeito do galhador, o abrigo às intempéries, notadamente a dessecação e outros efeitos adversos do ambiente, e a proteção aos inimigos naturais (PRICE et al. 1987). A adaptação a esta proteção determinou uma dependência da galha permanecer intacta, como primordial à sobrevivência do galhador, até mesmo ao seu final de ciclo. Os insetos cecidógenos têm uma biologia especializada e seu estudo é difícil, devido às dificuldades de sua criação artificial e acompanhamento de seu desenvolvimento, especialmente quando são endofíticos. Esta característica determina condições específicas ao seu ambiente de crescimento e à sua alimentação, de modo que as condições das cecídeas, nas quais se desenvolvem endofíticamente, dificilmente podem ser reproduzidas artificialmente. Esta é uma limitação metodológica importante pois a manipulação dos insetos com tal tipo de vida, decorre em mortalidade elevada, freqüentemente total, ao retirar o espécime da galha ou mesmo por destruição parcial desta.

Dentre estes insetos, num programa de controle biológico conduzido em convênio entre Cooperative National Park Resources Studies Unit, University of Hawaii at Manoa, Honolulu- HA- USA e a Fundação de Pesquisas Florestais do Paraná, Universidade Federal do Paraná, Curitiba- PR, BR, cecidógenos da planta foram selecionados como agentes promissores, dentre os quais Neotrioza tavaresi Crawford, 1925, que ataca as folhas.

Como o conhecimento dos eventos mais importantes relacionados à história de vida da espécie fitófaga e suas exigências são o ponto de partida para a determinação de seu potencial de emprego como inimigo natural (HARLEY \& FORNO 1992), o objetivo deste trabalho foi estudar a história de vida, nos aspectos relacionados à biologia, ao ciclo de desenvolvimento, à reprodução, às interações com a planta e com os parasitóides de $N$. tavaresi.

\section{MATERIALE MÉTODOS}

Os estudos foram conduzidos no Primeiro Planalto Paranaense (48 $58^{\circ}$ a $49^{\circ} 38 \mathrm{~W} ; 5^{\circ} 27^{\prime}$ a $25^{\circ} 35^{\prime}$ 'S), em altitudes entre 750-1200 m, com clima tipo Cfb (classificação de Köeppen). As características geográficas mais detalhadas da área podem ser encontradas em MAAK (1968) e PARANÁ (1987). As observações foram realizadas durante três ciclos do inseto, com viagens regulares a campo. $\mathrm{O}$ primeiro iniciou-se em agosto de 1997 e findou em dezembro de 1997, o segundo iniciou-se em outubro de 1997 e findou em dezembro de 1998 e o terceiro iniciou-se em agosto de 1999 e findou em dezembro do mesmo ano. No período de 1997-98, o ciclo completo do inseto foi acompanhado e coletou-se material vegetal com galhas, que foi fixado em meio FAA (JOHANSEN 1940) e conservado em álcool $70 \%$. A amostra mínima foi de 10 folhas por data, em amostra estratificada entre plantas, ramos e folhas. Posteriormente, as galhas foram dissecadas para obtenção dos insetos e o material vegetal foi seccionado e montado em lâminas para estudos histológicos em microscópio. Para lâminas semipermanentes de material fresco, seguiu-se a metodologia de BERLING \& MiKSCHE (1976) e para lâminas permanentes em glicol metacrilato (GMA), os procedimentos de Feder \& O'Brien (1968). Para observação dos adultos de $N$. tavaresi, estes foram retirados de folhas com galhas abertas e conservados em laboratório, sob temperatura média de $19,7{ }^{\circ} \mathrm{C}\left(16,0-25,3{ }^{\circ} \mathrm{C}\right)$ e umidade relativa média do ar de 70,9\% $(54,0-82,7 \%)$. Os adultos ficaram confinados em potes plásticos com diâmetro de $11 \mathrm{~cm}$ e altura de $8 \mathrm{~cm}$, cobertos com matelassê. Para alimentação foram fornecidas brotações de araçazeiro com a base cortada em bisel dentro de recipiente com água, trocadas diariamente. Casais em cópula foram isolados, usando-se fêmeas que iniciaram o processo de exaustão para a contagem da quantidade de ovos. $\mathrm{O}$ abdome foi aberto com agulha com ponta em bisel em solução de $\mathrm{NaCl}$ a $2 \%$ (peso) e $0,5 \%$ (volume) de detergente. Os ovaríolos foram rompidos e os ovos espalhados e dispostos em linha para contagem em estereomicroscópio com aumento de 50x. Para verificar a emergência do inseto de galhas em folhas abcisadas, utilizou-se dois tratamentos. No primeiro, 80 folhas foram recolhidas em 12/09/1997 sob as plantas e levadas para local semelhante àquele em que se encontravam (gramado sombreado). No segundo, outras 40 folhas foram colocadas em recipientes plásticos e as folhas sempre úmidas e mantidas em sala. Em 26/09/1997 foram dissecadas 50 galhas de cada tratamento para verificar o conteúdo.

\section{RESULTADOS E DISCUSSÃO}

Machos e fêmeas de Neotrioza tavaresi Crawford, 1925 não diferiram no comprimento do corpo pelo testes de $\mathrm{t}$ $\left(\left|\mathrm{t}_{\mathrm{n}=58}\right|=0,26 ; \mathrm{P}<0.80\right)$, com 3,78 $\pm 0,39 \mathrm{~mm}(\mathrm{n}=30$ machos +30 fêmeas), cor da cabeça e tórax cinzentos, abdome alaranjado e asas hialinas. Os sexos puderam ser diferenciados pelas gonapófises na parte terminal do abdome (Lima 1943), protuberantes e arredondadas nos machos e pontudas nas fêmeas. A quantidade de machos e fêmeas não diferiu quando comparadas suas diferenças numéricas através do teste de $\mathrm{t}$ $\left(\left|\mathrm{t}_{\mathrm{n}=17}\right|=1,08<\mathrm{t}_{0,10(15)}=1,75\right)$, confirmando a hipótese de nulidade e a razão sexual de 1, concordando com o citado por HODKINSON (1984) e Mensah \& Madden (1993) para outras espécies da família.

N. tavaresi apresentou ciclo univoltino, com a ocorrência de adultos na primavera, em sincronia com o período de brotação do araçazeiro. Os brotos foram as únicas partes da planta onde os adultos se alimentaram e realizaram postura. A infestação 
das ninfas recém eclodidas só ocorreu na brotação. Isto é comum na biologia dos insetos indutores de galhas, que são dependentes de estruturas vegetais ou de estádios específicos de desenvolvimento com tecidos reativos à indução onde inicia a galha e que ocorrem num período limitado do ciclo ou ano (HodKINSON 1984; Weis et al. 1988).

Os adultos foram liberados das galhas que apresentaram maior abertura em períodos com elevadas temperaturas e umidade do solo. Estas condições também favoreceram a brotação dos ramos. Dentro das galhas, os adultos estavam paralisados e após alguns minutos de sua abertura perderam o seu torpor e iniciaram o deslocamento caminhando, saltando e voando a curtas distâncias, demonstrando baixa capacidade de dispersão, concordando com relatos para outras espécies de psilídeos (CLARK 1962; White 1970).

A cópula teve inicio cerca de 15 minutos após a liberação dos adultos da galha, com o macho caminhando atrás da fêmea. Isto se repetiu algumas vezes e, após algumas tentativas, o macho subiu no dorso da fêmea e efetuou a cópula que demorou de 15 a mais de 60 minutos, com os extremos do abdome opostos.

Em condições de laboratório e de campo, adultos confinados com alimento iniciaram a morrer a partir do terceiro dia. A mortalidade foi rápida pois adultos confinados em ramos de plantas, com brotações adequadas à sua alimentação, foi de $71 \%$ aos 5 dias $(\mathrm{n}=620)$. O máximo de sobrevivência verificada foi de 11 dias em ambas condições.

As fêmeas avaliadas na contagem de ovos estavam sexualmente maduras, pois foram obtidas de galhas abertas e mantiveram cópula. $\mathrm{O}$ detergente na solução foi necessário para diluir a gordura do abdome e evitar que os ovos boiassem, facilitando sua separação na água. As fêmeas apresentaram cerca de uma centena de ovaríolos do tipo meroístico (sem células nutritivas circundando os oócitos) e teletrófico (a nutrição ocorre por uma corda presa no ovo e no germário), conforme características apresentadas em DAVEY (1985) E BÜNING (1994). Os ovaríolos não puderam ser contados pois, ao ser aberto o abdome, se romperam ou ficaram sobrepostos, de modo a não permitir sua individualização para uma verificação precisa. Nestes se encontraram oócitos em formação dentro da zona de crescimento previtelogênico durante a fase inicial em que o adulto permaneceu endofítico, com os ovos esverdeados, sem a presença de córion. Durante sua formação os ovos tornaramse gradativamente mais consistentes e passaram para coloração amarela na sua maturação. As fêmeas só apresentavam os óvulos totalmente desenvolvidos ao serem liberadas das galhas. Os ovários, cálices e os ovidutos estavam repletos de ovos que coloriram o abdome, em sua vista inferior, de amarelado. Nos ovaríolos foram encontrados geralmente um ou dois ovos maduros, sendo ausentes os ainda em formação na região de crescimento previtelogênico. Os ovos maturaram com muita uniformidade indicando que a postura deve ser rápida e concentrada, provavelmente devido ao pequeno tempo de vida do inseto fora da galha. A base do ovo era arredondada e apresentou um pedicelo introduzido no tecido com a função de fixação e hidratação (HODKINSON 1974, 1984; CARVER et al. 1991), ficando sua lateral encostada na superfície da folha. A postura só foi encontrada em brotações. Os ovos se localizaram na haste $(6,5 \%)$, pecíolo $(2,7 \%)$, lâmina $(90,8 \%)$ e, principalmente, borda adaxial da folha $(78,1 \%)$.

O número de ovos por fêmea foi de $218,7 \pm 44,67$ (média \pm desvio padrão) (123-305; $\mathrm{n}=50)$, demonstrando uma grande variação entre os indivíduos. Esta diferença entre fêmeas deve ser reflexo das condições de desenvolvimento das ninfas. Variações ainda maiores na quantidade de ovos por fêmea de outras espécies da família foram encontrados por TAYLOR (1962) e DeVI \& Praboo (1995). A ocorrência de acentuadas diferenças nas quantidades de ovos entre indivíduos de artrópodes é um evento bastante comum (Fox \& CZESAK 2000). As variações no tamanho dos ovos, obtidas das dimensões de comprimento e largura, mostram uma variação para as respectivas características de 6,5\% e 8,3\%. Estas diferenças foram menores que as verificadas entre número de ovos, que foi de $20,4 \%$. FOX \& CZESAK (2000) postulam que a herdabilidade do caráter relacionado ao tamanho do ovo é grande, enquanto que a de seu número é pequena, portanto com maior dependência do ambiente em que a fêmea se desenvolve. Destes fatores, a alimentação é um dos mais importantes e favorece tanto o tamanho da fêmea como o número e tamanho dos seus ovos. Diante de limitações impostas pelo ambiente onde se encontrava a fêmea durante seu crescimento e no período de formação dos ovos, o tamanho destes tendeu a permanecer mais constante, enquanto seu número diminuiu. Esta estratégia seria uma forma de ajustar o desempenho das formas jovens, uma vez que diminuir o tamanho dos ovos aumentaria a sua mortalidade e das ninfas emergidas.

A oviposição pode iniciar-se no dia seguinte ao da emergência e o comportamento de fêmeas observadas a campo foi a realização de postura em mais de um broto e, nestes, em várias folhas.

Brotos cortados e mantidos em recipientes com água, rapidamente perderam atratividade para alimentação e receberam poucos ovos, que tiveram elevada mortalidade. A mortalidade também foi elevada em brotações cortadas e colocadas com sua base dentro de recipientes com água. Assim, a condição do broto foi fundamental para a postura e sua viabilidade, e a fêmea pode detectar as alterações e diminuir sua alimentação e oviposição. TAYlor (1962), Clark (1963a, b), Mensah \& Madden (1993), Devi \& Praboo (1995) e Hodkinson (1997) igualmente relataram elevada seletividade das fêmeas para plantas hospedeiras e de suas partes antes da postura, que não ocorre se não encontrarem seu hospedeiro ou estruturas deste em estádios de desenvolvimento adequado.

Os adultos se alimentaram nos estádios iniciais dos brotos jovens, local onde também normalmente ocorreu a cópula e o único em que houve oviposição. Assim, além da seletividade da espécie de planta, também houve para o estádio da planta, que só foi infestada nos seus períodos iniciais de brotação, enquanto houve células em mitose e diferenciação dos tecidos vasculares do mesofilo da folha, constatados pelo estudo microscópico das seções.

Em torno de 7 a 10 dias após a postura houve a emergência 
do primeiro instar (N1). A ninfa pouco se deslocou na folha e iniciou sua alimentação no lado adaxial. De acordo com Luft \& PaIne (1997), as ninfas de Trioza eugeniae Froggatt (Hemiptera, Psyllidae) se deslocaram pouco para iniciar sua alimentação. CoBbinah (1986) constatou que ninfas de Phytolima lata Walker (Hemiptera, Psyllidae) se localizaram e permaneceram em folhas mais jovens, com maiores teores de $\mathrm{N}$ e menor de fibra, características mais favoráveis para se estabelecerem e completarem o ciclo antes de abcisão folhar. BALAKRISHNA \& RAMAN (1992) relataram que a ninfa de Diaphorina truncata Crawford, 1924 (Hemiptera, Psyllidae) deslocou-se pouco e, rapidamente, iniciou a alimentação nas células do mesofilo. $\mathrm{O}$ sedentarismo associado à alimentação é uma regra dentro de Sternorrhyncha, notadamente entre os cecidógenos. Como a alteração do tecido vegetal que formará a galha depende da picada e alimentação do inseto e de um período adequado para seu crescimento, a ausência de deslocamento da ninfa contribuiu para o sucesso nos eventos iniciais da formação da galha e do estabelecimento do inseto.

$\mathrm{O}$ exame do interior da galha revelou a presença uma loja ocupada por um indivíduo e de 5 exúvias, indicando que $N$. tavaresi atravessa 5 ínstares ninfais, regra nas espécies desta família (Lima 1943; Pesson 1951; HodKINSON 1984; CARVER et al. 1991). Muitas das exúvias de ninfas de N1 estavam ainda na lâmina da folha e as outras, subseqüentes, permaneceram aderidas numa bola de cera dentro da galha.

A Tabela 1 apresenta a porcentagem de fases de vida e os ínstares de $N$. tavaresi abrangendo 14 meses, de 14/10/1997 a 15/12/1998, com número mínimo de 105 e máximo de 144 insetos vivos por amostra. As amostras foram obtidas em intervalos aproximados de 1 mês, somando 1724 espécimens examinados ao longo do ciclo e seus meses de ocorrência estão sublinhados.

Os distintos ínstares do inseto ocorreram por um período longo de tempo, com destaque para N2 e N3, que foram encontradas por 8 meses, revelando uma grande variação no tempo que os indivíduos permaneceram em cada ínstar.

Em 14/10/1997 foram constatados, além de ovos, N1 livres e sendo envolvidas pelos tecidos. Das ninfas, $2 / 3$ estavam livres, externas à folha, a maioria se alimentava pois, ao serem mortas, ficaram com os estiletes presos ao tecido vegetal. Outro $1 / 3$ estava dentro de uma depressão no tecido da folha, com uma elevação característica da sua superfície adaxial e afundamento do inseto na lâmina. Em 12/11/1997, os ovos corresponderam a cerca de $13 \%$ do total dos indivíduos e as ninfas a $87 \%$. Destas últimas, a maioria ainda era livre, mas havia ninfas dentro das depressões e uma minoria já na condição endofítica. Em dezembro, não foram encontrados adultos, ovos, ou ninfas livres. As N1 já estavam todas estabelecidas nas depressões dos tecidos da folha e a maioria $(82,0 \%)$ estava dentro da loja da galha. Em janeiro ocorreu a primeira ecdise das ninfas e a maior parte passou para N2 (Tabela 1). Em fevereiro ocorreu $\mathrm{N} 3$, que corresponderam a mais da metade dos insetos observados em março, quando já não ocorreram N1. Em abril, ocorreu N4 e neste mês e em maio, houve aumento na proporção deste ínstar, no qual a maior parte da população atravessou o período hibernal. Em N4, o desenvolvimento da ninfa foi mais lento devido às baixas temperaturas, o que concorreu para que a maior parte das ninfas fosse deste ínstar.

Ao aumentar a temperatura e com a aproximação da primavera, os insetos passaram para N5, sendo este ínstar predominante $(91,1 \%)$ em setembro, período em que não se detectou mais N2. Em outubro, se constatou $60 \%$ de adultos endofiticos e galhas que se romperam e começaram a liberar os insetos sexualmente maduros. Isto indicou que o imago permaneceu dentro e se alimentou nos tecidos da galha, considerando estarem com os estiletes introduzidos na parede da galha no momento de sua dissecação, por um perído em torno de meio a 1 mês. Esta alimentação tanto propiciou a manutenção do adulto como a abertura das galhas, pois estas não se romperam quando o cecidógeno morreu como ninfa ou como imago. Adultos mortos foram encontrados dentro das galhas e, provavelmente, morreram logo após a ecdise, sem picar as paredes da galha, nem promover sua abertura. Em 22/ 10/1998 não ocorreu N3 e quase a totalidade das ninfas estava em N5, mas a maioria dos insetos $(60,0 \%)$ já estava na fase adulta e 13,6\% já eram adultos livres, estimados por galhas abertas. Neste período ocorreu a maior quantidade de diferentes ínstares do inseto. A proporção de adultos endofíticos aumentou até a segunda semana de novembro, a partir da qual seu número tendeu a diminuir, em função de sua liberação pelo rompimento das galhas. Em dezembro não ocorreram adultos nas galhas, mas no início deste mês foram constatados adultos

Tabela 1. Porcentagem de Neotrioza tavaresi em diferentes ínstares ao longo de seu ciclo em araçazeiro. Piraquara, PR, 1997-98.

\begin{tabular}{|c|c|c|c|c|c|c|c|c|c|c|c|c|c|c|c|}
\hline Data & $14 / 10 / 97$ & $12 / 11 / 97$ & $12 / 12 / 97$ & $20 / 01 / 98$ & $20 / 02 / 98$ & $25 / 03 / 98$ & $29 / 04 / 98$ & $25 / 05 / 98$ & $11 / 06 / 99$ & $20 / 07 / 97$ & $27 / 08 / 98$ & $19 / 09 / 98$ & $22 / 10 / 98$ & $14 / 11 / 98$ & $15 / 12 / 98$ \\
\hline Fase & & & & & & & & & & & & & & & \\
\hline Ovo & 66,7 & 13,4 & & & & & & & & & & & & & \\
\hline N1 & 33,3 & 86,6 & 100,0 & 20,7 & 4,6 & & & & & & & & & & \\
\hline N1 livre & 20,1 & 53,3 & & & & & & & & & & & & & \\
\hline N1 entrando & 13,2 & 29,5 & 18,0 & & & & & & & & & & & & \\
\hline N1 endo fítica & & 3,8 & 82,0 & 20,7 & 4,6 & & & & & & & & & & \\
\hline $\mathrm{N} 2$ & & & & 79,3 & 85,4 & 40,9 & 9,5 & 2,8 & 1,8 & 1,9 & 0,9 & & & & \\
\hline N3 & & & & & 10,0 & 59,1 & 39,1 & 16,1 & 11,9 & 8,7 & 3,8 & 3,6 & & & \\
\hline N4 & & & & & & & 51,4 & 80,2 & 82,5 & 86,5 & 84,9 & 37,3 & 3,6 & & \\
\hline N5 & & & & & & & & 0,9 & 3,8 & 2,9 & 10,4 & 59,1 & 36,4 & 5,3 & \\
\hline Adulto & & & & & & & & & & & & & 60,0 & 94,7 & 100,0 \\
\hline Adulto endofítico & & & & & & & & & & & & & 46,4 & 16,1 & \\
\hline Adulto livre & & & & & & & & & & & & & 13.6 & 78.6 & 100.0 \\
\hline Insetos vivos & 129 & 125 & 135 & 111 & 110 & 105 & 107 & 106 & 109 & 104 & 106 & 110 & 110 & 144 & 113 \\
\hline
\end{tabular}

$\mathrm{N}=$ ninfa. 


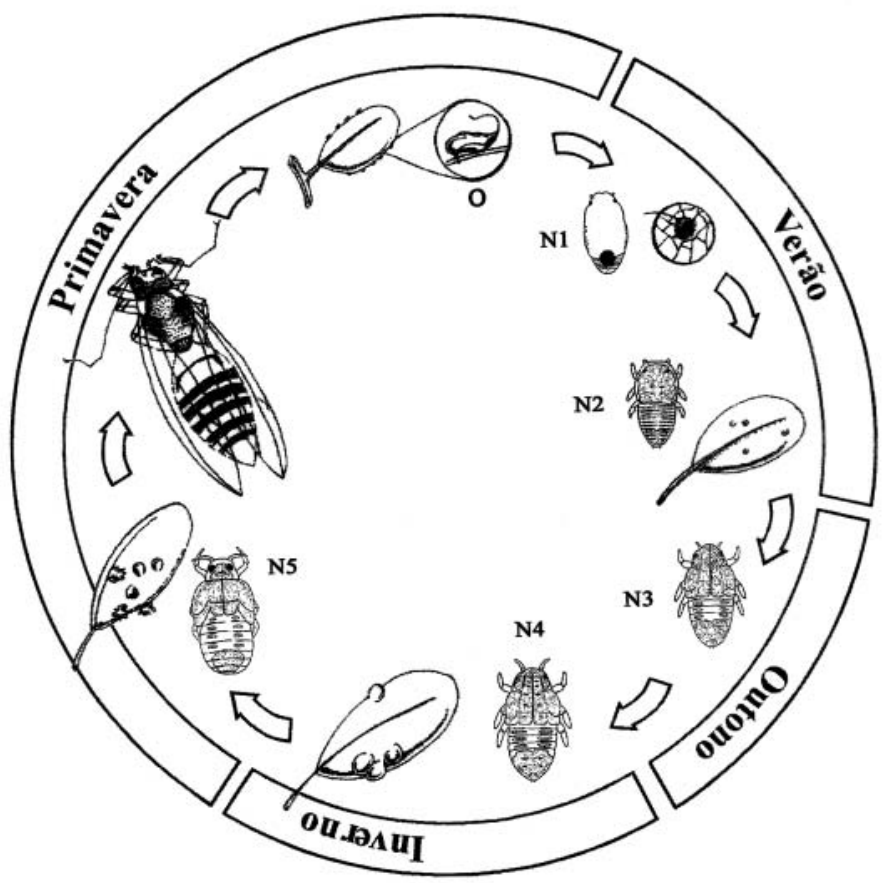

Fig. 1. Ciclo esquemático do cecidógeno Neotrioza tavaresi em araçazeiro. Piraquara-PR, 1997-98. $\mathrm{O}=$ ovo; N1=ninfa 1; N2= Ninfa 2; N3= ninfa 3; $\mathrm{N} 4=$ ninfa $4 ; \mathrm{N} 5=$ ninfa 5 . A escala de representação das fases de vida é variável.

nas brotações das plantas. Na Fig. 1 está representado esquematicamente o ciclo de $N$. tavaresi ao longo das estações.

Para a obtenção de adultos, o melhor período foi em outubro e novembro, pois sua proporção em relação à população foi maior, assim como a proporção dos que se encontravam maduros sexualmente. Os adultos devem ser obtidos das galhas em início de abertura, pois como exofíticos sua densidade foi muito baixa na planta e suas idades e condições fisiológicas, desconhecidas. Na mesma folha ou ramo, a sua idade deve ser mais homogênea devido à necessidade de períodos específicos do broto para postura e infestação das ninfas, o que contribuiu e reforçou a igualdade das idades dos insetos.

A sobrevivência de adultos de $N$. tavaresi dentro da galha foi maior que fora, provavelmente pela maior proteção que esta confere contra a dessecação e predação, que devem ser fatores muito limitantes. Ao abrir as galhas os adultos muitas vezes estavam cobertos de gotículas de água. Além disto, a possibilidade de alimentação nas paredes e a movimentação limitada do adulto deve manter suas reservas e sua longevidade.

$\mathrm{O}$ ciclo terminou em novembro, com a maioria dos insetos adultos já liberados pelas galhas, atingindo a totalidade um mês após, quando não houve mais insetos vivos nas galhas. A liberação do adulto endofítico, que só ocorreu em condições de ambiente que promoveram a brotação do novo ciclo do araçazeiro, evitou ao adulto riscos de ambiente adverso e de predação.

Ao final do ciclo, especialmente a partir de setembro, ocorreu grande quantidade de abcisão de folhas, muitas com galhas fechadas e insetos vivos no seu interior. As galhas secaram após as lâminas da folha e isto ocorreu devido à sua grande vascularização que garante o suprimento de seiva. Nas galhas das folhas mantidas em laboratório a desidratação foi mais lenta e houve 31 ninfas e 15 adultos vivos. Destes últimos, um estava terminando a ecdise e dois ainda mantinham a coloração esverdeada de recém terem atingido tal fase.

A umidade se mostrou importante para prolongar a turgescência das galhas nas folhas abcisadas e a vida de $N$. tavaresi. Insetos em folhas destacadas das plantas foram encontrados vivos até 25 dias depois de sua coleta. Embora ninfas pudessem permanecer vivas e até atingir a fase adulta, os insetos morreram, pois não houve nenhuma ruptura de galha em folhas abcisadas ou destacadas da planta.

Em exames de cortes histológicos, se constatou que a alimentação da N1, em função da introdução dos estiletes e injeção de saliva, provocou a lise de células da epiderme e mesofilo e iniciou um estímulo de hipertrofia das células próximas do local da picada. Estas modificações no padrão de diferenciação das células da folha são atribuídas a substâncias injetadas com a saliva do inseto (MiLes 1972; Hori 1992), mas os mecanismos completos de controle do desenvolvimento das distintas galhas entomógenas ainda não são totalmente conhecidos (Ananthakrishnan 1984; Cornell 1983; ROHFRITSCH 1992).

Após a hipertrofia das células próximas à picada, seguiu-se uma intensa hiperplasia, que decorreu em elevação das células da hipoderme e parênquima paliçádico, que entraram em processo de divisão, com intensas divisões anticlinais. Estes novos tecidos se projetaram ao redor da ninfa e, enquanto cerraram a abertura, empurraram a superfície da folha para baixo, o que provocou seu afundamento nos tecidos circundantes da ninfa e acabaram por envolvê-la, tornado-a endofítica. Tal processo caracterizou a formação de uma galha do tipo históide (Fig. 2), nas quais se constata ocorrência de hipertrofia, hiperplasia, e metaplasia, ou também denominada prosoplásmica, pois as camadas da parede da galha estavam

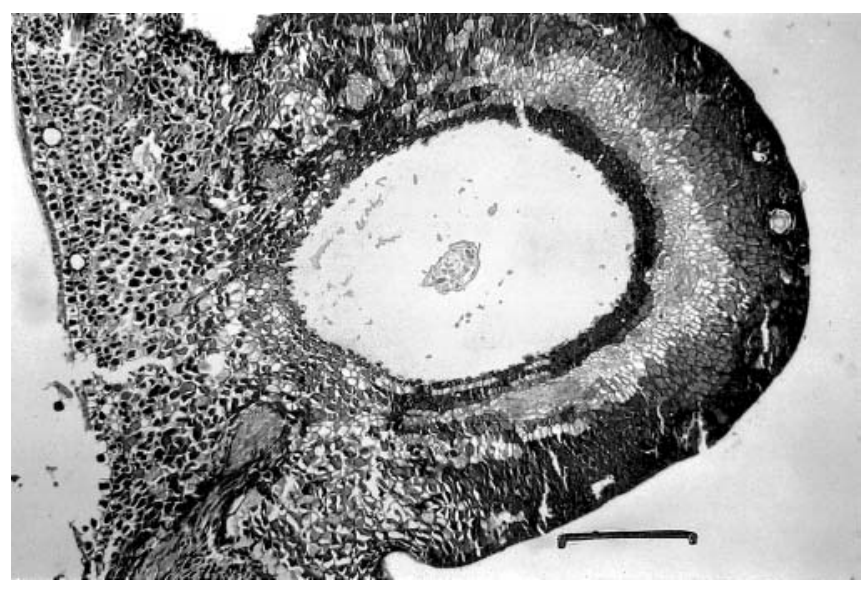

Fig. 2. Seção de galha de Neotrioza tavaresi causada em folha de araçazeiro, 100x. O inseto está no segundo ínstar e no centro da loja, e a parede da galha apresenta camadas diferenciadas. Piraquara-PR, 1998. Barra= $200 \mu \mathrm{m}$. Emblocamento em paraplast e coração com fucsina básica. 
Tabela 2. Porcentagem de ocorrência de classes de galhas na folha de araçazeiro, com ínstares vivos de Neotrioza tavaresi. Piraquara, PR, 1997-98.

\begin{tabular}{|c|c|c|c|c|c|c|c|c|c|c|c|c|c|c|c|}
\hline Data & $14 / 10 / 97$ & $12 / 11 / 97$ & $12 / 12 / 97$ & $20 / 01 / 98$ & $20 / 02 / 98$ & $25 / 03 / 98$ & $29 / 04 / 98$ & $25 / 05 / 98$ & $11 / 06 / 99$ & $20 / 07 / 97$ & $27 / 08 / 98$ & $19 / 09 / 98$ & $22 / 10 / 98$ & $14 / 11 / 98$ & $15 / 12 / 98$ \\
\hline \multicolumn{16}{|l|}{ Fase } \\
\hline Ausente: ninfa livre & 20,1 & 53,3 & & & & & & & & & & & & & \\
\hline Depressões & 13,2 & 29,5 & 18,0 & & & & & & & & & & & & \\
\hline Sinais & & & 82,0 & 20,7 & 4,6 & & & & & & & & & & \\
\hline Galha 1 & & & & 79,3 & 85,4 & 40,9 & 19,6 & 5,8 & 4,6 & 5,8 & 2,8 & & & & \\
\hline Galha 2 & & & & & 10,0 & 59,1 & 38,3 & 22,1 & 16,5 & 11,5 & 3,8 & 4,5 & & & \\
\hline Galha 3 & & & & & & & 37,4 & 62,5 & 58,8 & 51,2 & 22,6 & 19,1 & 9,9 & 4,9 & \\
\hline Galha 4 & & & & & & & 4,7 & 9,6 & 20,1 & 31,5 & 70,8 & 76,4 & 75,7 & 32,6 & \\
\hline Galha aberta & & & & & & & & & & & & & 14,4 & 62,5 & 100 \\
\hline Insetos vivos & 129 & 125 & 135 & 111 & 110 & 105 & 107 & 106 & 109 & 104 & 106 & 110 & 110 & 144 & 113 \\
\hline
\end{tabular}

Em 14/10 e 12/10 há ovos somados aos insetos vivos.

$\mathrm{D}=$ depressão causada por ninfa 1 ; G1=galha com pedicelo e diâmetro até 3,0 mm; G2=galha com diâmetro entre 3,1-4,0 mm; G3=galha com diâmetro entre 4,0-5,5 mm; G4=galha com diâmetro >5,5 mm; G1:4= soma G1 a G4.

bem definidas, que são as com forma e padrão característico, formadas principalmente por insetos (MEYER \& MARESQUELLE 1983).

A parte interna da galha não teve um parênquima interno limitante e dos tecidos da parede, diferenciados sob influência das ninfas de $N$. tavaresi, se desenvolveu uma grande quantidade de tecido parenquimático e vascular, com predominância de floema no último. Nestas camadas mais internas, foi onde o inseto se alimentou. Nas paredes externas houve elementos de proteção como aumento no número de drusas, no tamanho e número de glândulas de óleo, idioblastos com grande quantidade de compostos fenólicos e células esclerenquimáticas, que é um padrão comum nas galhas prosoplásmicas (MEYER \& MARESQUELle 1983; RoHFRITSCH 1992). A cecídea teve loja única com um inseto no seu interior. Na sua maturidade, a galha mediu 6-8 $\mathrm{mm}$ de diâmetro e a parede em torno de $1 \mathrm{~mm}$ de espessura.

Em amostragem de 86 ramos de 20 plantas infestadas, foram encontrados 52 com galhas $(60,5 \%)$ e, de suas 858 folhas, 181 $(21,1 \%)$ apresentaram cecídeas. A média de galhas por folha infestada foi de 6,3 e variância de 129,3 (1-69), indicando grande variação no seu número devido à distribuição agregada do inseto, pois a variância é superior à média das amostras (KUNO 1991).

A proporção em porcentagem das estruturas perceptíveis exteriormente formadas pelo efeito morfogênico da alimentação, nas quais foram detectados os insetos vivos, estão na Tabela 2. As galhas foram classificadas em depressão (D), caracterizada pela elevação dos tecidos circundantes da N1 e afundamento da superfície folhar abaixo do local em que esta se encontrou; sinal (S) ao ocorrer o fechamento da galha e a projeção da face abaxial da folha, isolando o inseto no interior da loja; G1 (galha 1) quando ocorreu a formação do colo da galha e o diâmetro desta foi inferior a 3,0 mm; G2 para galhas com diâmetro entre 3,1- 4,0 mm; G3 com diâmetro 4,1 - 5,5 mm; G4 com diâmetros maiores que 5,5 mm. As galhas no seu período de crescimento máximo e início da abertura, apresentaram diâmetro de 6-8 mm.

Até o mês de março houve uma total coincidência entre estruturas e ínstares ninfais, após N1 iniciar a modificação das células ao seu redor ou seu afundamento na folha. Todas N2 estiveram em G1 e todas N3 estiveram em G2. A partir de abril, ocorreu um aumento na velocidade do desenvolvimento das galhas, que mudaram de classe mais rapidamente que os insetos mudaram de ínstar. A distribuição dos ínstares entre as classes de galhas apresentou, deste mês em diante, uma dispersão maior na distribuição das porcentagens entre os tipos de galhas, que entre os ínstares de desenvolvimento do inseto. G4 apareceu em abril com insetos em N4, mas em datas subseqüentes, G3 pode conter insetos adultos, o que tornou a relação entre o ínstar do inseto e o crescimento da galha menos associada. Apenas no final do ciclo, com a galha aberta, há a certeza do sucesso do adulto com a sua liberação.

Os parasitóides atacaram a fase ninfal e todas as espécies encontradas pertencem a Hymenoptera. De Encyrtidae, foram obtidas 2 espécies de Caldencyrtus e uma espécie de Psyllaephagus. De Eulophidae, ocorreu 1 espécie de Tetrastichinae, e de Pteromalidae, 2 espécies. A predominância foi dos endoparasitóides Caldencyrtus sp. 1 e Caldencyrtus sp. 2 (Encyrtidae), constatados pela múmia de N5, que somaram $96,4 \%$ dos parasitóides encontrados nas galhas. Caldencyrtus sp. 1 representou $76,6 \%$ dos indivíduos deste gênero. As espécies restantes foram ectoparasitóides, portanto detectados pela observação de sua larva ou pupa.

Os galhadores possuem uma das mais complexas faunas de parasitóides, tanto do ponto de vista sistemático, incluindo várias famílias, quanto biológico, com elevada quantidade de hiperparasitóides (PRICE et al. 1987), o que pode contribuir para o desconhecimento da biologia e correta relação entre o inseto e sua atividade na galha.

\section{CONCLUSÕES}

O ciclo de $N$. tavaresi foi sincronizado com o das plantas de araçazeiro. A presença de brotações em grande número e em estádios iniciais de desenvolvimento, se mostrou favorável à sua infestação por $N$. tavaresi, pois os adultos facilmente encontraram local de alimentação, cópula e postura e as ninfas encontraram tecidos moles, nutritivos e reativos para a formação de uma galha complexa do tipo prosoplásmica. A ninfa de $N$. tavaresi deve permanecer viva para a galha prosseguir no seu desenvolvimento, bem como o adulto, para haver sua abertura. 
Agradecimentos. Ao Dr. David Hollis do The Natural History Museum pela determinação do psilídeo e ao Prof. Ayres Menezes Jr. do Departamento de Agronomia da Universidade Estadual de Maringá, pela identificação dos parasitóides. Ao Cooperative National Park Resources Studies Unit, Hawaii University at Manoa, Honolulu- HA- USA pelo apoio financeiro e à Fundação de Pesquisas Florestais do Paraná pelo apoio administrativo. À Direção da Sanepar- Piraquara- PR, por permitir o uso da área dos Manancial da Serra.

\section{REFERÊNCIAS}

Abrahamson, W. G. \& K. D. McCrea. 1986. The impact of galls and gallmakers on plants. Proceedings of the Entomological Society of Washington 88(2):364-367.

Ananthakrishnan, T. N. 1984. Biology of gall insects. New Delhi, Oxford \& IBH, 362 p.

Balakrishna, P. \& A. Raman. 1992. Cecidogenesis of leaf galls of Strychnos nux-vomica (loganiaceae) induced by the jumping plant louse species Diaphorina truncata (Homoptera: Psylloidea: Psyllidae). Entomologia Generalis 17(4):285-292.

Berling, G P. \& Miksche, J. P. 1976. Botanical microtechnique. Ames, Iowa State University.

BünING, J. 1994. The insect ovary: ultraestructure, previtellogenic growth and evolution. London, Chapman \& Hall, $400 \mathrm{p}$.

Carver, M.; G. F. Griss \& T. E. Woodward. 1991. Hemiptera, p. 429-509. In: Division of Entomology (Commonwealth Scientific and Industrial Research Organization). The insects of Australia. Melbourne, Melbourne \& Cornell University Press, v.1, 642 p.

Clark, L. R. 1962. The general biology of Cardiaspina albitextura (Psyllidae) and its abundance in relation to weather and parasitism. Australian Journal of Zoology 10(4):537-586.

Clark, L. R. 1963a. Factors affecting the attractiveness of foliage for oviposition by Cardiaspina albitextura (Psyllidae). Australian Journal of Zoology 11(1):20-34.

Clark, L. R. 1963b. The influence of population density on the number of eggs laid by females of Cardiaspina albitextura (Psyllidae). Australian Journal of Zoology 11(1):190-201.

CoBbinah, J. R. 1986. Factors affecting the distribuition and abundance of Phytolima lata (Homoptera:Psyllidae). Insect Science and its Application 7(1):111-115.

Cornell, H. V. 1983. The secondary chemistry and complex morphology of galls formed by the Cynipidae (Hymenoptera): why and how? American Midland Naturalist 110(2): 225-234.

Davey, K. G. 1985. The female reproductive tract, p. 15-36. In: G. A. Kerkut, \& L. I. Gilbert (eds.). Comprehensive Insect Physiology, Biochemestry and Pharmacology, vol. I. Embriogenensis and reproduction. Oxford, Pergamon Press, 487 p.

Devi, D. S. \& N. R. Prabhoo. 1995. Biology of leaf gall forming Pauropsylla tuberculata (Homoptera). Journal of Ecobiology 7(1): 75-77.

Feder, N. \& O'Brien, T. P. 1968. Plant microtechnique: some principles and new methods. American Journal of Boyany 55(1):123-142.

Fox, C. W. \& M. E. CzesaK. 2000. Evolutionary ecology of progênie size in arthropods. Annual Review of Entomology 45: 341-369.

Harley, K. L. S. \& I. W. Forno. 1992. Biological control of weeds. A handbook for practioners and students. Brisbane, CSIRODivision of Entomology, 74 p.

Harris, P. \& J. D. Shorthouse. 1996. Effectiveness of gall inducers on weed biological control. Canadian Entomologist 128(6):10211055 .

Hodkinson, I. D. 1974. The biology of the Psylloidea (Homoptera): a review. Bulletin of Entomological Research 64(2):325-339.

QúóšruvúuẾX́X̂̀O. 1984. The biology and ecology of the gall-forming Psylloidea (Homoptera), p. 59-77. In: T. N. AnANThaKRishnan (ed.). Biology of galls insects. New Delhi, Oxford \& IBH, $262 \mathrm{p}$.

Hodkinson, I. D. 1997. Progressive restriction of host plant exploitation along a climatic gradient: the willow psyllid Cacopsylla groelandica in Greenland. Ecological Entomology 22(1): 47-54.

Hori, K. 1992. Insect secretions and their effect on plant growth, with special reference to hemipterans, p.157-170. In: J. D. SHPRThouse \& O. Rohfritsch (eds). Biology of insect-induced galls. New York, Oxford University Press, $285 \mathrm{p}$.

Johansen, D. A. 1940. Plant microtechnique. New York, McGraw Hill, $523 \mathrm{p}$.

Kuno, E. 1991. Sampling and analyses of insect pest populations. Annuel Review of Entomology 36: 285-304.

Legrand, C. D. \& R. M. Klein. 1977. Mirtaceas, p. 573-930. Flora ilustrada catarinense. Itajaí.

Lima. A. DA C. 1943. Insetos do Brasil. Homópteros. Tomo 3. Rio de Janeiro, Escola Nacional de Agronomia, 327 p.

Luft, P. A. \& T. D. Paine. 1997. Behavioral cues associated with oviposition by Trioza eugeniae. Entomologia Experimentalis et Applicata 84(3):293-299.

MAAK, R. 1968. Geografia física do Estado do Paraná. Curitiba, CODEPAR, $350 \mathrm{p}$.

Mensah, R. K. \& J. L. Madden. 1993. Life story and biology of Ctenarytaina thysanura Ferris and Klyver (Hemiptera: Psyllidae) on Boronia megastigma Nees ex Bartl. (Rutaceae) in Tasmania. Journal of the Australian Entomological Society 32(4): 327-337.

Meyer, J. \& H. J. Maresquelle. 1983. Anotomie des galles. Stuttgart, Gebrüder Borntraeger, $662 \mathrm{p}$.

Miles, P. W. 1972. The saliva of the Hemiptera. Advances in Insect Physiology 9:183-256.

Paraná. 1987. Atlas do Estado do Paraná. Curitiba, Secretaria da Agricultura e do Abastecimento, $73 \mathrm{p}$.

Pesson, P. 1951.Ordre des Homoptères, p. 1390-1656. In: P. -P. Grassé (ed.). Traité de Zoologie. Tomo X. Paris, Masson \& Cie., 1948 p.

Price, P. 1997. Insect Ecology. New York, Jonh Wiley \& Sons Inc., $874 \mathrm{p}$.

Price, P. W.; G. L. Warning \& G W. Fernandes. 1987. Adaptative nature of insects galls. Environmental Entomology 16(1):15-24.

RohFritsch, O. 1992. Patterns in gall development. p. 60-86. In: J. D. Shorthouse \& O. Rohfritsch (eds.). Biology of insect-induced galls. New York, Oxford, 285 p.

Roskam, J. C. 1992. Evaluation of the gall-inducing guild, p.34-49. In: J. D. Shorthouse \& O. Rohfritsch (eds.). Biology of insect-induced galls. New York, Oxford, $285 \mathrm{p}$.

TAYLOR, K. L. 1962. The Australian genera Cardiaspina Crawford and Hyalinaspis Taylor (Psyllidae: Homoptera). Australian Journal of Zoology 10(2):307-348.

Weis, A. R.; R. Walton \& C. Greco. 1988. Reactive plant tissue sites and the population biology of gall makers. Annual Review of Entomology 33:467-486.

White, T. C. R. 1970. Some aspects of the life story, host selection, dispersal, and oviposition of adult of Cardiaspina densitexta (Homoptera: Psyllidae). Australian Journal of Zoology 18(1): 105-117.

Wikler, C. 1999. Distribuição geográfica mundial de Psidium cattleianum Sabine e um cecidógeno com possibilidades de utilização em controle biológico. Tese de doutorado. Universidade Federal do Paraná, Curitiba, PR. 